\title{
A PESQUiSA PARA CONSERVAÇÃO DE SUPERFÍCIES ARQUITETONNICAS DO MUSEU CASA DE RUI BARBOSA
}

\author{
Claudia S. Rodrigues de Carvalho
}

68 Essas pesquisas vêm sendo desenvolvidas, sob nossa orientação, com bolsistas do Programa de Incentivo à Produção do Conhecimento Técnico e Científico na Área da Cultura da FCRB, o qual pretende formar, treinar e capacitar recursos humanos em programas de desenvolvimento tecnológico, de referência em preservação e tratamento de acervos, assim como em humanidades. A pesquisa para Conservação das Superfícies Arquitetônicas vem sendo desenvolvida desde 2009, e contou com a colaboração dos bolsistas: arquitetos MSc Maria da Glória de Souza Brandão (outubro de 2009 a março de 2012) e, MSc, Thiago Turino, de agosto de 2010 a dezembro de 2011.

\section{INTRODUÇÃO}

O Museu Casa de Rui Barbosa, no Rio de Janeiro, é um monumento protegido pela legislação nacional de preservação. Desde sua concepção arquitetônica e construção, há mais de 150 anos, a edificação vem passando por inúmeras transformações, que estão relacionadas, principalmente, aos processos históricos, de uso, de envelhecimento natural de seus materiais constitutivos e das agressões ambientais decorrentes das transformações de seu entorno. Nos anos 70, a Casa foi submetida a extensas obras de restauração, que atingiram a totalidade do edifício, destacando-se a introdução de extensas áreas cimentadas nas fachadas. O desconhecimento da extensão das mudanças resultantes dessas intervenções, incluindo as variações de cores e detalhes, bem como alterações na integridade das alvenarias, motivou o desenvolvimento de uma pesquisa, cujo objetivo é estabelecer parâmetros para conservação das superfícies arquitetônicas, alinhando a correta definição de princípios e diretrizes ao aumento da qualidade da execução e ao controle de contratos e gestão de obras desse tipo. Este artigo apresenta um panorama das atividades desenvolvidas no âmbito da referida pesquisa, que envolve também a definição de estratégias para a experimentação, treinamento e capacitação, no campo da preservação do patrimônio edificado.

O Museu Casa de Rui Barbosa integra a Fundação Casa de Rui Barbosa, instituição vinculada ao Ministério da Cultura e tem, como missão, promover a preservação e a pesquisa da memória e da produção literária e humanística, bem como congregar iniciativas de reflexão e debate acerca da cultura brasileira.

Desde o final dos anos 90, as ações de preservação do Museu Casa de Rui Barbosa buscam integrar o edifício histórico e as coleções que abriga, tendo como base a prevenção, e estão consubstanciadas no Plano de Conservação Preventiva do Museu Casa de Rui Barbosa.

A partir de 2005, uma linha de pesquisa passou a apoiar as ações do referido plano - estratégias de conservação preventiva para edifícios históricos que abrigam coleções, e suas ações abrangem a identificação do patrimônio tutelado pela instituição, em sua historicidade, composição e materialidade; a avaliação dos riscos para sua preservação; o desenvolvimento de métodos para prevenção e tratamento; e a criação de instrumentos didáticos, para difusão da conservação preventiva no Brasil. No âmbito dessa ação, foram realizadas pesquisas aplicadas para a conservação programada das coberturas e dos elementos de madeira; das alvenarias e seus revestimentos internos, com enfoque nos papéis de parede; e encontra-se em desenvolvimento a pesquisa para conservação das superfícies arquitetônicas externas. ${ }^{68}$

As superfícies arquitetônicas da Casa de Rui Barbosa apresentam inúmeras dificuldades para sua conservação/restauração, considerando o valor de patrimônio da edificação, sua função atual como museu, e o fato de as superfícies atuais, embora não sendo as originais, possuírem historicidade e conformarem o valor figurativo do monumento, nas últimas quatro décadas. Em 2008, a fachada 
de uma parte do conjunto edificado do museu - a antiga cavalariça - foi objeto de intervenção de restauro de suas superfícies internas e externas, tendo o projeto indicado a utilização de argamassas à base de cal, para substituir as áreas com argamassa de cimento deteriorada, dado que a utilização de argamassas à base de cal vem apresentando bons resultados como argamassas de substituição para a conservação de superfícies históricas (KANAN, 2008), e, a partir daquela experiência, foi estabelecida uma estratégia para preservação das demais fachadas, envolvendo pesquisa, experiências de campo, treinamento e educação.

As superfícies arquitetônicas encerram importante significância cultural do patrimônio edificado, na medida em que conferem identidade, favorecem a percepção dos volumes e a apreciação da composição, refletem a cor, textura, acabamento e estilo de uma época, registram técnicas e métodos construtivos, além de protegerem as fachadas das agressões do meio ambiente.

As superfícies arquitetônicas exteriores, comumente entendidas como superfícies de sacrifício, vêm sendo objeto de discussões conceituais e técnicas para sua conservação. Há pelo menos quatro décadas, verifica-se um crescente interesse pela preservação dos revestimentos e cores das fachadas, notadamente no continente europeu. Em nosso País, verifica-se também o desenvolvimento de estudos e pesquisas, para o melhor conhecimento da constituição das superfícies tradicionais, materiais e técnicas construtivas, bem como a adoção de métodos de conservação alinhados com as posturas internacionais. No entanto, o entendimento de seu valor figurativo, adquirido com o transcurso do tempo e seu reconhecimento como registro histórico, requerem uma capacidade de avaliação nem sempre presente, como ressalta B. Kühl:

Sinais de transcurso do tempo são cada vez menos apreciados em nossa sociedade. Com essa tendência atual à renovação e à pasteurização de superfícies, muito se perde da riqueza e da vibração resultantes dos próprios métodos de execução tradicionais de argamassas e de pinturas e dos "acidentes" da vida de uma obra. Deve-se lembrar que o objetivo de uma restauração não é oferecer uma imagem do passado facilmente consumível, simplificada de forma grosseira para se tornar mais palatável ao gosto massificado. É, ao contrário, explorar e valorizar toda a riqueza das estratificações da história. Isso pode ser alcançado por meio do ato histórico-crítico, antídoto para a tendência atual de se voltar para cores frívolas - que em nosso ambiente muitas vezes se está traduzindo em cores berrantes, que chegam a impedir a própria apreciação do bem, tal a cacofonia que impõem à obra - ou para cores amorfas, que não se relacionam com as características tectônicas e de composição da obra. [...] (KÜHL, 2004)

O entendimento desses aspectos plurais fazem da conservação das superfícies um problema teórico e prático de restauração, e que não pode ser considerada apenas como manutenção ordinária. Trata-se de uma ação que envolve tanto a forma quanto a matéria do edifício, e não deve ser executada como mero tratamento cenográfico; ao contrário, deve considerar o objeto arquitetônico como um todo, em sua complexidade funcional, estética e estrutural (CARBONARA, 1997). É preciso salvaguardar a técnica, a funcionalidade e os aspectos estéticos, sendo indicado um projeto para a intervenção que contemple um conhecimento 
minucioso da história, da técnica e do estado de conservação desses revestimentos, articulando diversos campos do conhecimento.

São escassos os documentos que tratam da metodologia de projeto de restauração/conservação das superfícies arquitetônicas exteriores, mas existe, dentre os trabalhos que buscam uma sistematização (TAVARES, 2009), o entendimento que as intervenções devem seguir os princípios correntes da conservação, quais sejam: o respeito pela autenticidade material, não só dos aspectos originais, mas dos acréscimos introduzidos em seu transcurso no tempo; a identificação de patologias; a intervenção mínima, sempre que possível, evitando remoções e substituições; a distinguibilidade, pois a intervenção de conservação/ restauração altera sua materialidade; a utilização de materiais compatíveis, química, física e mecanicamente; a elaboração de um sistema de documentação de performance pós-intervenção, que subsidie um programa de manutenção, garantindo a sustentabilidade da preservação.

As soluções para os problemas devem ser baseadas na compreensão da materialidade das paredes e revestimentos, nas causas da deterioração e na compatibilidade dos materiais de intervenção. O processo decisório, no caso das superfícies do Museu Casa de Rui Barbosa, demanda uma abordagem crítica e um aprofundamento técnico, de modo que a intervenção não se restrinja a minimizar os problemas de deterioração e atender exclusivamente às necessidades funcionais. Nesse sentido, tem-se discutido as seguintes questões:

- Quais são os valores históricos e arquitetônicos das superficies arquitetônicas do Museu Casa de Rui Barbosa?

- Os revestimentos mudaram o significado histórico arquitetônico e a integridade da edificação?

- O edifício ainda guarda evidência dos revestimentos originais, que poderiam guiar o projeto de conservação/restauração?

- Qual a composição e o grau de compatibilidade das argamassas aplicadas nos anos 70? Os danos atingem as alvenarias, e em qual extensão?

- Qual é o risco envolvido na remoção das argamassas existentes? Há técnica disponível?

- Qual a tecnologia a ser empregada nas argamassas de substituição? As técnicas tradicionais serão eficazes e suficientes no futuro?

- Haverá mão de obra disponível, para manutenção da estrutura no futuro, de modo a garantir a sustentabilidade da ação pretendida?

Com o objetivo de fornecer informações suficientes e coerentes, em resposta a essas questões, propusemos um plano de pesquisa com o seguinte desenvolvimento (CARVALHO; KANAN, 2010):

$1^{a}$ Fase: Levantamento e análise tipológica, incluindo levantamentos arquivístico e bibliográfico; inspeções in loco, para identificar técnicas, material de construção, fases de construção; análise tipológica, para avaliar as características das superfícies arquitetônicas da casa.

$2^{a}$ Fase: Diagnóstico, incluindo identificação e avaliação do estado de conservação, causas da deterioração, características dos materiais.

$3^{a}$ Fase: Fase experimental e análises laboratoriais, incluindo documentação, caracterização física e composição dos materiais originais e substratos, a fim de determinar a formulação das argamassas de substituição; pesquisar fontes de materiais e fornecedores; revisão da literatura, para avaliar abordagens atuais para especificação e avaliação das propriedades dos materiais disponíveis, e desenvolver formulações, para serem testadas. 
$4^{a}$ Fase: Treinamento/Capacitação, visando à formação de mão de obra qualificada, por meio de oficinas de capacitação, para melhoria do nível técnico dos profissionais envolvidos.

$5^{\text {a }}$ Fase: Avaliação crítica e estabelecimento de parâmetros técnicos e procedimentos para os projetos e intervenções futuras.

Em 2011, demos início à pesquisa "Conservação das superfícies arquitetônicas do Museu Casa de Rui Barbosa", a partir da contratação de bolsista por processo seletivo, conforme citado anteriormente. Alinhada com o conjunto de trabalhos que visam sistematizar as ações de preservação do monumento, foi definida a seguinte metodologia de trabalho (CARVALHO, 2010):

1 - Levantamento e consolidação de informações, incluindo a atualização do cadastro do monumento, acrescentando informações sistemáticas sobre sua estrutura, materiais e técnicas construtivas; consolidação dos dados relativos à investigação histórica, bibliográfica e iconográfica sobre a edificação e seu uso; identificação de acréscimos e remoções no tecido histórico.

2 - Análise tipológica e formal, para definição das especificidades das superfícies arquitetônicas do Museu Casa de Rui Barbosa, relativas à permeabilidade, à textura, à tonalidade, à luminosidade, à consistência e à transparência, entre outros aspectos que devem ser considerados no processo de conservação.

3 - Diagnóstico de conservação, identificação e mapeamento de patologias específicas, utilizando métodos científicos, quando necessário.

4 - Estabelecimento de parâmetros para execução de conservação de superfícies arquitetônicas históricas, contemplando a identificação dos acréscimos a remover; identificação dos elementos originais a serem conservados; identificação dos elementos perdidos que deverão ser reintegrados; identificação dos tratamentos das patologias específicas.

5 - Definição dos procedimentos técnicos para a conservação das superfícies, incluindo experimentação e monitoramento.

Seguindo a metodologia proposta, foram realizadas a pesquisa arquivística e bibliográfica, o registro das intervenções anteriores, o estudo da envolvente do edifício, a análise tipológica, inspeções visuais e análise estratigráfica de alguns trechos da fachada. Os resultados dessa etapa, ainda em fase de consolidação, demonstram que as superfícies arquitetônicas externas - fachadas - do Museu Casa de Rui Barbosa sofreram alterações significativas no transcurso do tempo, notadamente em função de intervenções ocorridas após a década de 1970, quando foram introduzidos materiais e técnicas distintos dos originalmente usados na construção do edifício, principalmente as argamassas à base de cimento e as tintas à base de óleo e acrílicas, que eram práticas correntes de preservação. As informações sobre as intervenções realizadas nos períodos anteriores a essa data são incompletas e inconsistentes, sendo também muito fragmentadas e difusas, as informações conhecidas sobre a concepção e construção da Casa, o que deixa grandes incertezas sobre as características construtivas originais da mesma.

Os problemas decorrentes da utilização de argamassas de cimento, para restauração de edifícios construídos com materiais tradicionais, já são bem conhecidos, como explica R. Veiga:

Assim, as argamassas de cimento apresentam um aspecto final muito diferente das argamassas antigas, em termos, por exemplo, da textura da superfície, do modo como reflectem a luz. Para além disso, é sabido que contêm na sua composição sais solúveis que são transportados para o 


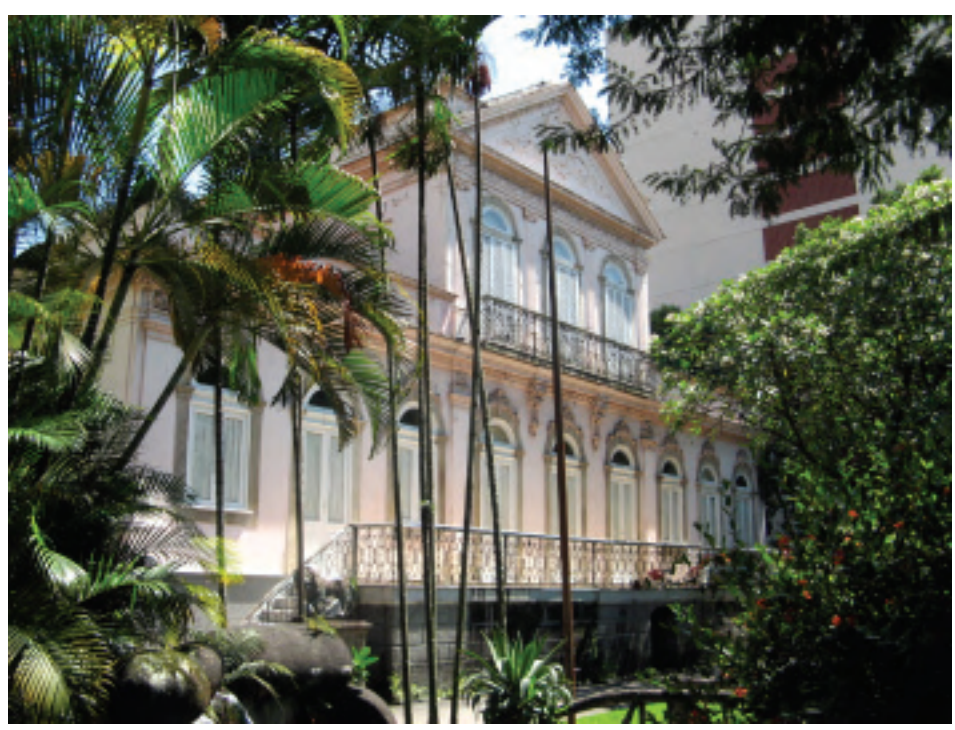

Figura 1: Fachada principal Museu Casa de Rui Barbosa, dezembro 2011 Fonte: Arquivo FCRB, por Thiago Turino

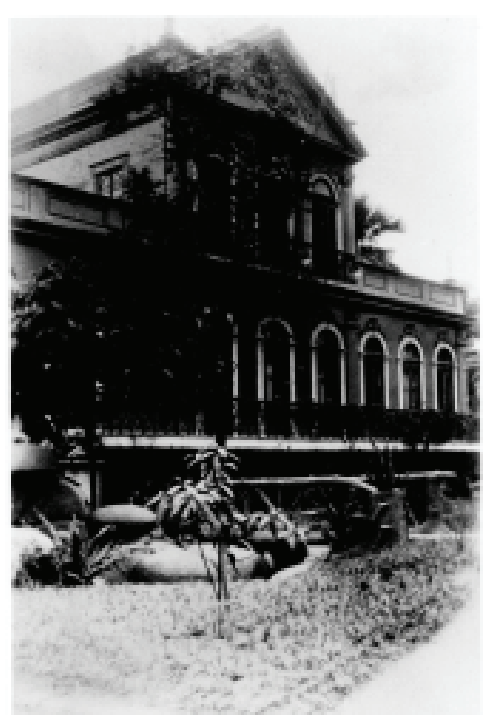

Figura 2: Fachada principal Casa de Rui Barbosa, s/data Fonte: Arquivo FCRB

interior das paredes e lá cristalizam, contribuindo para a sua degradação. Tem-se verificado que também outras características sãos desfavoráveis, como uma rigidez excessiva e uma capacidade limitada de permitir a secagem da parede [...] (VEIGA, 2003)

Sabe-se, ainda, que a utilização de revestimentos cimentícios afeta mais as estruturas expostas a condições de umidade mais severas - altos índices pluviométricos -, e as estruturas com alto teor de umidade em seu interior, provocado pela variação dos níveis do lençol freático e deficiências nas coberturas. As paredes podem ficar saturadas de umidade, sob a capa impermeabilizante dos revestimentos cimentícios, o que acelera o processo de deterioração.

Na etapa referente à identificação das patologias, procedeu-se a um diagnóstico de conservação, incluindo mapeamento de danos e análises in situ da caracterização das superfícies. Verifica-se que a incompatibilidade dos materiais utilizados e as agressões ambientais afetaram mais a parte inferior das superfícies, constituída por uma argamassa cimentícia com acabamento do tipo "chapiscado", com pintura plástica na cor cinza escuro, que constitui uma capa impermeável para o embasamento da construção. Nesse trecho, as principais patologias identificadas são a perda da coesão e a perda da aderência, e um agravamento na condição das alvenarias, com a presença de sais. Segundo M. Tavares:

As principais causas de deterioração de um revestimento exterior são, em geral, as mesmas que afetam as estruturas arquitetônicas. A deterioração de um revestimento ocorre devido a vários fatores: físicos, mecânicos, químicos ou biológicos, sendo uma das principais formas de degradação a perda de coesão, que é a perda de resistência mecânica de camadas do reboco, devido à perda ou alteração dos traços de ligação entre as partículas; e a perda de aderência, que é a separação ou destacamento que pode ocorrer entre as diferentes camadas de um reboco ou entre o 


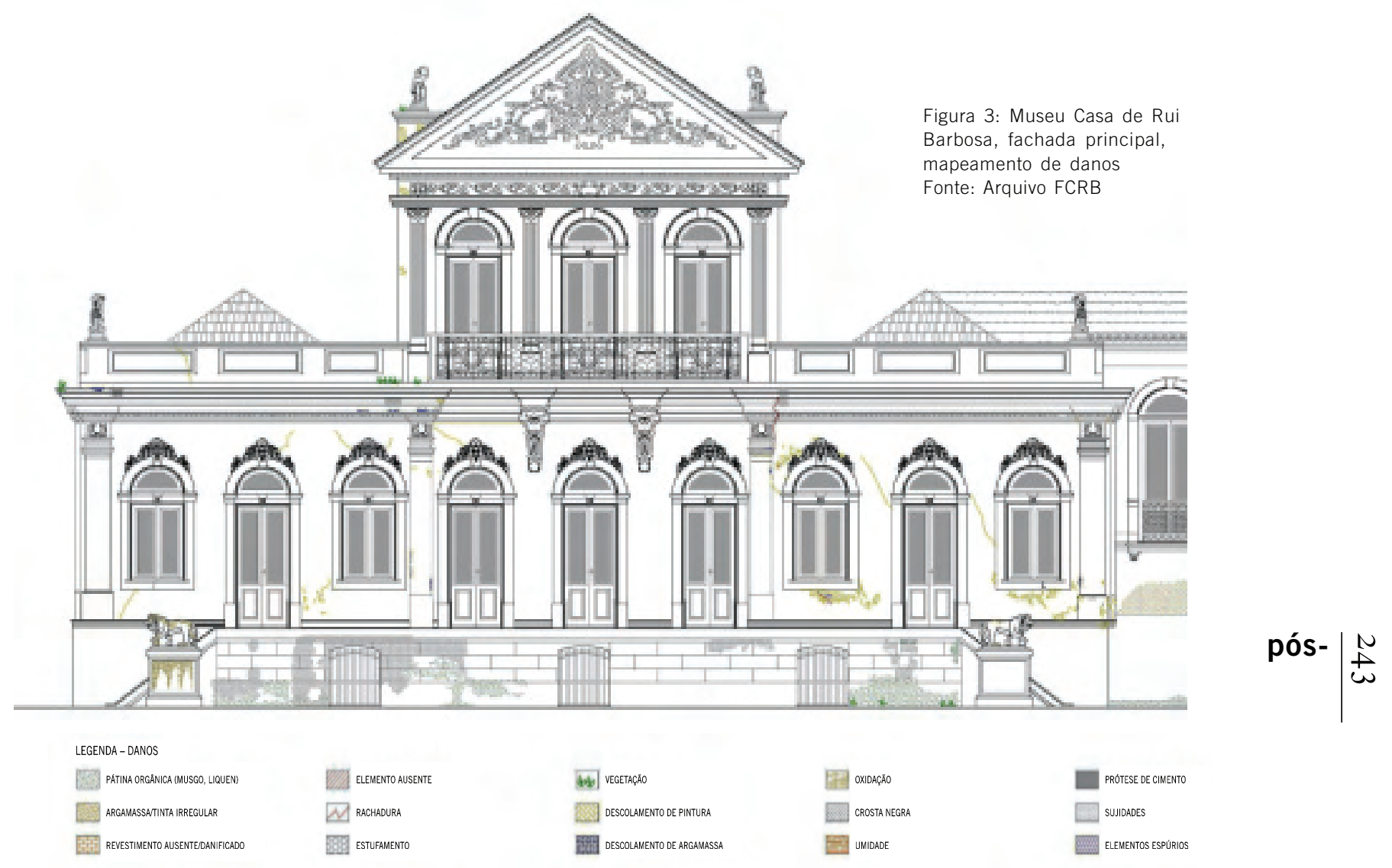

reboco e o suporte. Estas degradações provocam no revestimento o surgimento de várias anomalias: descamação, destacamento, descolamento, desagregação, enfarinhamento, pulverulência, fissuração e lacunas [...] (TAVARES; AGUIAR; VEIGA, 2005)

$\mathrm{Na}$ parte superior das fachadas, com revestimento em argamassa de cimento e acabamento em pintura acrílica na cor rosa-salmão, a situação, verificada até agora por inspeção visual, apresenta danos aparentes de menor proporção, sendo os principais problemas referentes às camadas de pintura, e não às camadas de revestimento. Exames de percussão e análises laboratoriais serão conduzidos, para que se atinja um diagnóstico mais conclusivo em relação ao estado de conservação das alvenarias nesse trecho.

Normalmente, as argamassas de cimento devem ser eliminadas, mas ainda não atingimos, no estado atual da pesquisa, o entendimento de quais seriam os reais danos provocados por sua remoção, sendo necessárias outras análises. Em princípio, a estratégia de conservação em exame é a aplicação de argamassas de substituição, para conservação do trecho inferior da fachada, correspondente ao embasamento, e, na parte superior, adotaríamos a consolidação do reboco e a aplicação de nova pintura, mais permeável.

Argamassa à base de cal vem sendo empregada, com bons resultados, para a conservação/restauração de edifícios históricos, porque apresentam plasticidade, porosidade, permeabilidade, resistência mecânica, inércia térmica, são duráveis, quando bem executadas, aplicadas e mantidas, e ainda envelhecem sem provocar danos. 
A contribuição das análises de laboratório, para o estudo das técnicas de restauro, é muito significativa, no que tange à formulação de argamassas de substituição; no entanto, existem dificuldades técnicas na aplicação dessas argamassas, que só poderão ser superadas a partir de pesquisas, experiências de campo, treinamento e educação. Desse modo, será possível também estabelecer métodos de análise in situ do revestimento, para conhecimento de sua técnica, de sua história e de seu estado de conservação, especificar melhor as distintas técnicas de restauro, identificar materiais compatíveis com o revestimento e que sejam economicamente viáveis, e testar produtos disponíveis no mercado.

Nesse sentido, procedemos a uma etapa experimental, utilizando uma variação de argamassas de emboço e reboco, diversos tipos de acabamento e texturas, bem como diversas pinturas, com a intenção de conhecer melhor o comportamento dos revestimentos exteriores à base de cal, verificar sua eficácia e estabelecer especificações para as argamassas de substituição que serão empregadas para a conservação das superfícies arquitetônicas do Museu Casa de Rui Barbosa.

Baseados em levantamento bibliográfico sobre o tema e no diagnóstico de conservação da edificação, foram definidos os testes a serem realizados em muro existente no jardim do Museu. O referido muro, cujas características construtivas guardam grande semelhança com as das paredes externas do museu - alvenaria de pedra com argamassa de barro e cal -, apresentava danos decorrentes de queda de árvore no jardim. Procedeu-se sua recuperação e sua preparação para a aplicação das argamassas-teste, reproduzindo, assim, as condições reais das fachadas, principalmente nos requisitos de aderência e permeabilidade.

Sabe-se que a preparação do suporte, bem como as técnicas para preparação e aplicação das argamassas, conjugadas às condições ambientais e de cura contribuem para a qualidade dos revestimentos, tanto quanto os materiais empregados e sua formulação. O desenvolvimento e aplicação das argamassas seguiram os padrões tradicionais de misturas, cura, armazenamento e aplicação (KANAN, 2008). Foram desenvolvidas, em oficina, as formulações das argamassasteste, assim como foram orientados os funcionários da empresa contratada quanto aos procedimentos técnicos a serem observados.

As argamassas são materiais constituídos,

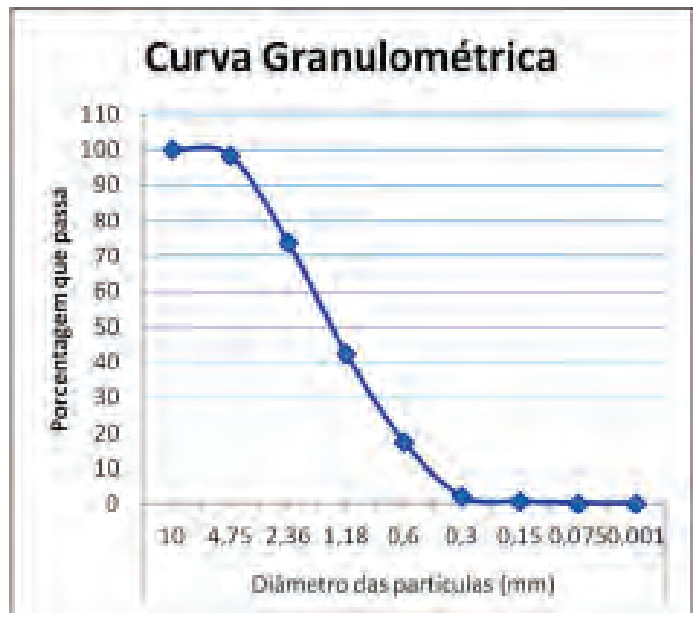

Figura 4: Curva granulométrica da areia utilizada nas argamassas de teste Fonte: Arquivo FCRB basicamente, de dois componentes: o aglomerante e o agregado. Ocasionalmente, também se emprega um aditivo. A cal foi um dos materiais mais importantes, na construção de alvenarias tradicionais, ao longo de centenas de anos. No entanto, o progressivo desaparecimento dos meios de produção e da mão de obra com conhecimento e habilidade técnica, somado às facilidades que o uso do cimento trouxe ao mercado contribuíram para que a cal fosse sendo substituída pelo cimento. A utilização da cal em obras de restauração impõe um domínio de sua tecnologia, para que se alcancem os resultados desejados (VEIGA, 2003).

O primeiro parâmetro definido foi o tipo de areia a ser utilizada. As areias influenciam o comportamento das argamassas, em função de sua granulometria e, principalmente, de sua origem. Utilizou-se uma areia de origem conhecida, lavada e livre de impurezas (barro, galhos, etc.). Para garantir uma boa coesão entre 
Tabela 1: Formulação das argamassas-teste Fonte: Arquivo FCRB agregado e aglomerante, foi feita a curva granulométrica da areia, para garantir um equilíbrio em sua composição.

Na sequência, foram definidos os tipos de cales que seriam utilizados e a formulação dos diversos traços. Importava também, na execução dos testes, que se pudessem comparar os materiais e as técnicas tradicionais de formulações das argamassas com os produtos à base de cal industrializados. Sendo assim, chegouse a quatro grupos de argamassas, sendo dois com cal virgem e dois com cal industrializada.

Para facilitar a aplicação e as análises, a superfície do muro-teste foi subdividia em quatro painéis, e em cada painel foram aplicadas variações das formulações, conforme descrito a seguir:

1 - Argamassas-teste, grupo A - utilizou-se a forma tradicional e muito conhecida pelos profissionais de restauro, isto é, a pasta de cal virgem, apagada em canteiro e deixada em repouso por dois meses. No emboço, a pasta de cal virgem foi misturada com areia de granulometria inferior a $4,75 \mathrm{~mm}$, com três variações de traços. Nesse grupo, foram empregados dois tipos de acabamento: 0 primeiro, um reboco pigmentado, com areia de granulometria inferior a $1,18 \mathrm{~mm}$, no traço de 1:1,5; e o segundo, uma pintura à base de cal pigmentada, com a adição de uma quantidade pequena de areia de granulometria inferior a 0,300 $\mathrm{mm}$, no traço de 1:0,5.

2 - Argamassas-teste, grupo B - utilizou-se uma técnica menos comum: cal virgem em pó apagada em canteiro com areia, em proporções e granulometria definidas para cada traço. Após o preparo, essa argamassa ficou em repouso por uma semana, antes da aplicação. A granulometria da areia utilizada foi a mesma do grupo A (inferior a 4,75 mm), com três variações de traço. Foram aplicados reboco e pintura com as mesmas formulações utilizadas nas argamassas-teste do grupo $A$, sendo, a única diferença, de a cal ter sido apagada com a areia e 0 pigmento.

3 - Argamassas-teste, grupo C - utilizou-se cal hidratada industrializada, de categoria $\mathrm{CH}-\mathrm{I}$ (NBR 7175). Para melhorar o desempenho do material e auxiliar na comparação entre os materiais, a cal hidratada foi também imersa em água e deixada em repouso por dois meses, da mesma forma que a cal virgem. Os traços do emboço variaram em cada painel, e a granulometria da areia utilizada foi a mesma do grupo $A$, inferior a $4,75 \mathrm{~mm}$. No reboco, repetiu-se a mesma formulação anteriormente utilizada nos grupos A e B. Já a pintura de cal foi feita com o uso dos produtos desenvolvidos pelo mesmo fabricante da cal, permitindo, assim, uma comparação com a formulação tradicional.

\begin{tabular}{|c|c|c|c|c|c|c|}
\hline \multicolumn{7}{|c|}{ Formuloçẫo de Algamesses - Testes } \\
\hline \multirow[t]{2}{*}{ Grupo } & \multicolumn{6}{|c|}{ Tracos Utilisados } \\
\hline & $\begin{array}{l}\text { Pasto de col virgem } \\
\text { imerso em } 6 \text { gua por } 2 \\
\text { meses }\end{array}$ & Cal virgem em pó & $\begin{array}{l}\text { Col inductrializodo } \\
\text { imerso em dguo por } 2 \\
\text { meses }\end{array}$ & $\begin{array}{l}\text { Aceio de gromulometria } \\
\text { inferior a } 4,75 \mathrm{~mm}\end{array}$ & $\begin{array}{l}\text { Reboco pigmentodo of } \\
\text { orelo de granulometria } \\
\text { inferior o } 1,18 \mathrm{~mm}\end{array}$ & $\begin{array}{l}\text { Pintura } d / \text { areia de } \\
\text { gronulometria inferior a } \\
0,03 \mathrm{~mm}\end{array}$ \\
\hline A1 & 1 & & & 2.5 & $1: 1,5$ & \\
\hline A2 & 1 & & & 3 & $1: 1.5$ & \\
\hline A3 & 1 & & & 4 & & $1: 0.5$ \\
\hline B1 & & 1 & & 3 & $1: 1.5$ & \\
\hline B2 & & 1 & & 4 & & \\
\hline B3 & & T & & 5 & $1: 1.5$ & \\
\hline C1 & & & 1 & 2.5 & & $1: 0.5$ \\
\hline $\mathrm{C} 2$ & & & 1 & 3 & & \\
\hline $\mathrm{C}_{3}$ & & & 1 & 4 & & \\
\hline D1 & \multicolumn{6}{|c|}{ Segundo es especticacóses e malefiois do fabricarie } \\
\hline D2 & \multicolumn{6}{|c|}{ Segundo as especticacobes e moteribis do fobelcante } \\
\hline
\end{tabular}


4 - Argamassas-teste, grupo D - utilizou-se argamassa de cal hidráulica pronta (produto seco), com adição de água na proporção especificada pelo fabricante. 0 acabamento utilizado foi a pintura com tinta de silicato, do mesmo fabricante, com a adição de pigmento.

O processo de execução foi acompanhado e registrado em relatório, pela equipe de pesquisa. Todas as etapas de formulação e aplicação foram detalhadas, item a item, na ordem de execução, para não haver erros ou dúvidas no canteiro. Após o preparo, as argamassas ficaram acondicionadas em tonéis plásticos, por uma semana, antes da aplicação. Em cada tonel foi acrescido um filete de água na superfície das argamassas, para evitar o ressecamento.

Após a formulação de todas as argamassas, iniciou-se a fase de aplicação, que consistiu em limpeza da superfície com uma trincha - para remoção da poeira e sujidades -, umidificação, lançamento (chapar) da argamassa com a colher de pedreiro, usando bastante impacto, para facilitar a aderência dos materiais. As

Figura 5: Preparo das argamassas-teste grupo A Fonte: Arquivo FCRB, por Thiago Turino

Figura 7: Argamassa-teste grupo A1 - acabamento desempenado para 0 emboço

Fonte: Arquivo FCRB, por Thiago Turino

Figura 8: Argamassa-teste grupo D - Aspecto final Fonte: Arquivo FCRB, por Thiago Turin
Figura 6: Aplicação de argamassa-teste, grupo A2 Fonte: Arquivo FCRB, por Claudia Carvalho
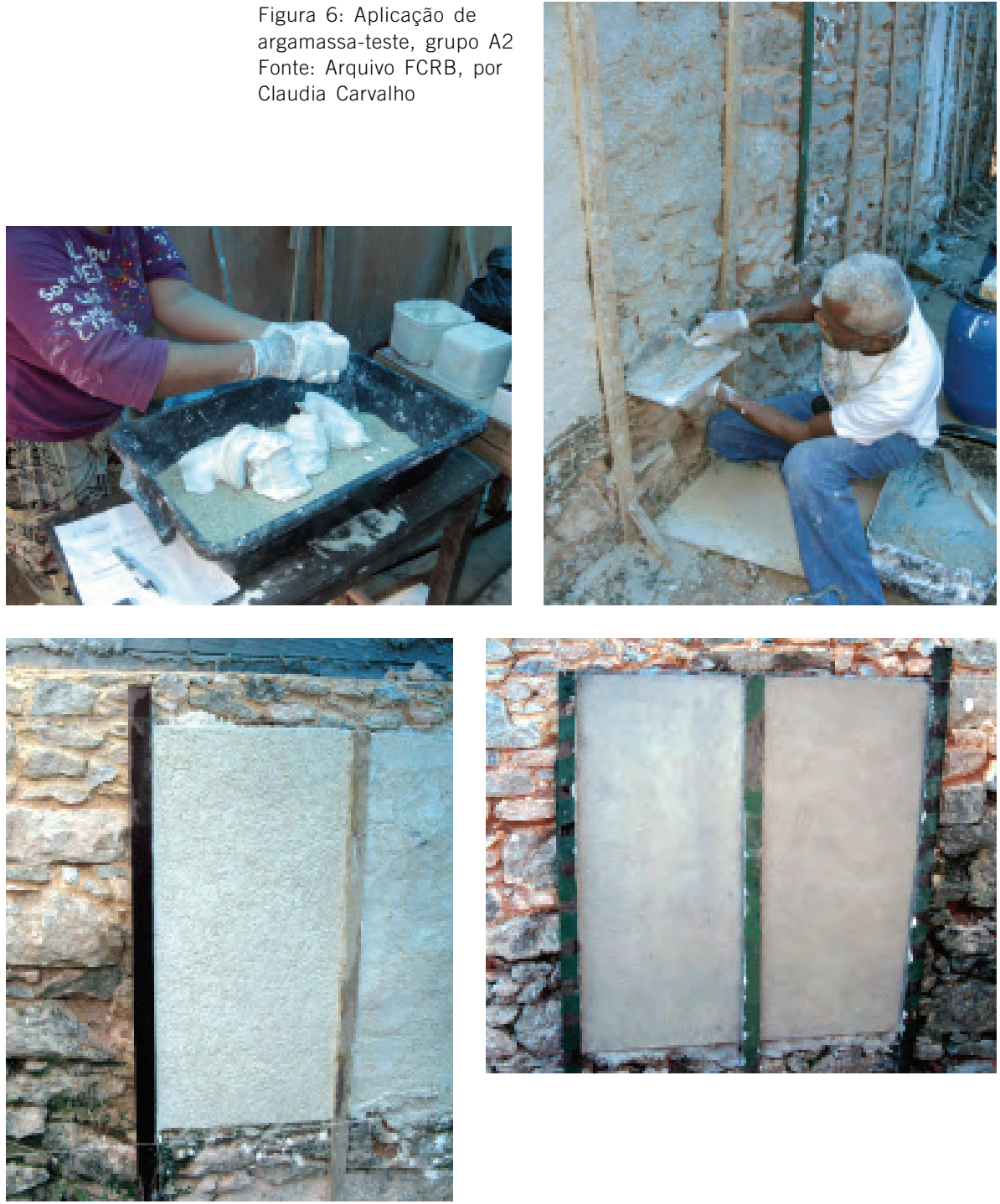

PÓS V.I9 N.3I - S ̃̃O PAULO • JUNHO 2012 
argamassas foram aplicadas em duas camadas (chapisco e emboço), sendo dado acabamento com desempenadeira de plástico, na última camada.

As argamassas do grupo A apresentaram uma consistência seca no momento da aplicação, com uma trabalhabilidade menor, o que dificultou o trabalho. As argamassas do grupo B apresentaram consistência e aparência bem diferentes das demais, mais brancas e mais pastosas, o que facilitou o lançamento e a aderência ao suporte, mas, por seu peso, apresentaram rachaduras quando da superposição de camadas. As argamassas do grupo $\mathrm{C}$ apresentaram uma maior plasticidade $\mathrm{e}$ facilidade ao serem lançadas na parede, por apresentar uma proporção maior de pasta de cal.

A argamassa do tipo D apresentou textura muito fina, criando um aspecto simular à argamassa do tipo "cimentcola". A aplicação foi bastante facilitada por sua trabalhabilidade, e o tempo de pega mais lento que as demais, sendo necessário aguardar um dia para aplicação da segunda camada de argamassa, e algumas horas para o acabamento final. $\mathrm{O}$ aspecto final da superfície nada se parecia com as argamassas aplicadas nos outros painéis. A argamassa apresentava uma aparência muito lisa e uma coloração cinza, o que levantou a possibilidade da presença de algum tipo de aditivo não revelado pelo fabricante.

Após a aplicação das argamassas-teste, os painéis foram monitorados por seis meses, e, findo esse período, foram recolhidas amostras para análises laboratoriais.

O planejamento para monitorar o comportamento das argamassas-teste seguiu as recomendações de manuais (TEUTONICO, 1988) para monitoramento visual, com o uso de técnicas e materiais de fácil acesso. Iniciadas no preparo das argamassas e com duração prevista para um ano após a aplicação, as análises se referem à trabalhabilidade, o teor de água, o tempo de cura, a retração, a carbonatação, a dureza (resistência a abrasão), a coesão, a variação da cor e da textura.

Durante os dois primeiros meses de observação após a aplicação, as variantes de acabamentos aplicadas nas argamassas-teste do grupo A apresentaram uma boa coesão, homogeneidade na cor e textura. $\mathrm{O}$ acabamento de pintura apresentou algumas marcas do pincel, mas foi considerado normal para o material empregado. O emboço apresentou coesão menor, mas, após a aplicação do reboco e da pintura, o resultado foi satisfatório. A argamassa não apresentou nenhuma fissura, descolamento, ou outro tipo de patologia que comprometesse sua qualidade. Apesar do desprendimento de grãos de areia, no período inicial da observação, consideraram-se satisfatórias sua dureza e compacidade. Em relação aos aspectos visuais de cor, textura e homogeneidade do acabamento final, os resultados das argamassas do grupo A foram considerados muito satisfatórios.

A maior questão, no uso desse grupo de argamassa nas futuras intervenções das fachadas do Museu, poderá ser a dificuldade de trabalhar-se com a cal virgem, que deve ser extinta e mantida imersa por, no mínimo, um mês, para alcançar um bom desempenho.

As argamassas-teste do grupo B apresentaram mudança significativa no revestimento de emboço. Retrações deram lugar a rachaduras perceptíveis a distância (já na aplicação, foram verificadas fissuras), causadas, provavelmente, pela quantidade de água na formulação das argamassas, e o tempo de descanso reduzido. Dentre as argamassas de reboco desse grupo, a que apresentou um comportamento mais satisfatório foi a argamassa-teste grupo B 3, por apresentar uma maior proporção de areia (traço 1:5), o que reduziu a retração e, consequentemente, o número de fissuras foi menor. Quanto à dureza e coesão, 
esse grupo de argamassas-teste apresentou um resultado muito satisfatório e as argamassas se mostraram muito homogêneas, em função de a cal ter sido apagada com a areia. Já em relação ao acabamento, o reboco se apresentou mais homogêneo em relação à cor e menos em relação à textura; a pintura apresentou um resultado pouco homogêneo, em relação à cor e textura. A falta de prática na formulação desse tipo de argamassa de cal suscita dúvidas em relação à sua utilização em larga escala.

As argamassas-teste do grupo $\mathrm{C}$ apresentaram bons resultados em relação ao emboço, no que se refere à coesão, à dureza e à retração. Já os acabamentos não tiveram o mesmo desempenho. 0 reboco apresentou uma textura homogênea, mas ocorreu uma leve variação de cores. Nas pinturas, os resultados foram bastante inferiores, tanto nas cores, que variaram muito, quanto na textura, muito irregulares.

A argamassa-teste do grupo $D$ apresentou resultados muito diferentes, em relação às demais. A textura mais lisa, muito semelhante a uma argamassa de cimento, a cor mais acinzentada, o material altamente coeso e dureza bem inferior. A pintura empregada nessa argamassa, à base de silicato de potássio, apresentou uniformidade em relação à cor e à textura, mas seu acabamento, um pouco acetinado, pode comprometer o resultado, quando usada em grandes áreas.

O monitoramento contínuo, durante um ano, permitirá também avaliar a durabilidade, em relação às variações climáticas do local. Após seis meses da aplicação, isto é, ao final do ciclo de carbonatação das argamassas, amostras de todos os painéis foram enviadas para testes laboratoriais.

Os resultados verificados nessa etapa experimental deverão ser complementados com os resultados das análises laboratoriais, que revelarão características das argamassas que o monitoramento visual não pode identificar, indicando qual caminho a seguir, para o aprimoramento das formulações.

$\mathrm{Na}$ conservação de superfícies arquitetônicas, a primeira opção a ser considerada é a manutenção dos revestimentos existentes, tendo em vista o papel que desempenham na significação cultural do patrimônio edificado. Reparos pontuais ou ainda operações de consolidação são as principais estratégias, nesses casos. Na impossibilidade de manter-se o revestimento existente, a definição de uma argamassa de substituição comporta um grau de complexidade, no que se refere aos requisitos funcionais que devem ser atendidos, porque o novo revestimento deve adequar-se à especificidade de cada situação: a tipologia da

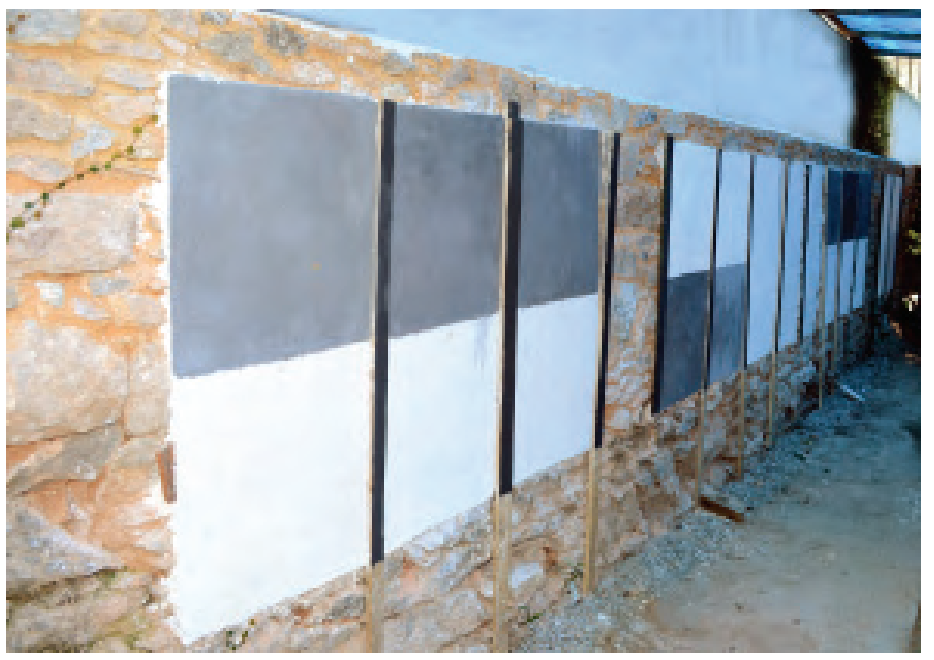

Figura 9: Vista geral da parede-teste Fonte: Arquivo FCRB, por Cláudia Carvalho 
edificação, a época de sua construção, as características dos materiais que constituem o suporte, o clima e as condições ambientais. Permeiam, ainda, esse quadro de exigências funcionais, critérios de ordem estética e figurativa, que, necessariamente, devem estar embasados no julgamento histórico-crítico da obra a ser preservada.

A intervenção para conservação de alvenarias que foram revestidas com cimento por longo período de tempo requer investigação científica e deve ser guiada por princípios gerais da restauração, sob pena do comprometimento irremediável de sua autenticidade, dos registros históricos originais ou acrescidos, dos valores formais e figurativos e das marcas da passagem do tempo, que consubstanciam sua significação cultural.

A remoção das argamassas cimentícias, em função dos graves problemas que causam nas alvenarias tradicionais, é normalmente recomendada, bem como a utilização de argamassas de substituição à base de cal, mais compatíveis e favoráveis à preservação. No caso específico das superfícies arquitetônicas do Museu Casa de Rui Barbosa, trata-se de remover uma adição e fazer outra, isso porque, ainda que os novos revestimentos empregados sejam compatíveis e apresentem materiais e técnicas tradicionais, trata-se de uma ação do presente e não um retorno às técnicas originais, pressupondo o tempo como reversível, e assim essa ação deve basear-se nos princípios teóricos e técnicos da preservação do patrimônio cultural.

Em nossa proposta, prevalece a intenção de intervir o mínimo possível na materialidade das superfícies, preservando ao máximo a imagem consolidada do monumento nas últimas décadas, sem provocar rupturas, favorecendo, com base em critérios técnicos e científicos, sua permanência e continuidade.

Pretende-se, assim, sistematizar procedimentos que previnam e evitem a necessidade de intervenções de maior porte e que permitam controlar, de modo racional, as transformações do edifício, em estreita relação com a natureza dos materiais, as características técnicas e a interação com o ambiente circundante.

\section{REFERÊNCIAS}

CARBONARA, Giovanni. II trattamento delle superfici come problema di restauro. In: Avvicinamento al restauro. Napoli: Liguori, 1994, p. 511-519.

CARVALHO, Claudia S. R., KANAN, Maria Isabel. Conservation and Restoration of the Casa de Rui Barbosa Museum's architectural surfaces in Rio de Janeiro: reflections and planning issues. In: Proceedings of the $2^{\text {nd }}$ Historis Mortars Conference and of the Final Workshop TC 203-RHM.Bagneux: RILEM Publications s.a.r.l, 2010. p. 565-572.

CARVAlho, Claudia S. R. Plano de Conservação Preventiva do Museu Casa de Rui Barbosa: Conservação das Superfícies Arquitetônicas do Museu Casa de Rui Barbosa. Projeto de Pesquisa para - Programa de Incentivo à Produção do Conhecimento Técnico e Científico na Área da Cultura da FCRB, disponível em http://www.casaruibarbosa.gov.br/dados/DOC/bolsistas/2010/ FCRB_Selecao_de_Bolsistas_2010_Conservacao_Superficies_Arquitetonicas.pdf

FLORES-COLEN, Inês; MAGALHÃES, Ana Cristina; VEIGA, Rosário. Técnicas de ensaio para a avaliação do desempenho de argamassas de revestimento aplicadas em paredes correntes e antigas. In: Anais do IX SBTA - Seminário Brasileiro de Tecnologia de Argamassas. Belo Horizonte: Antac, 2011.

fragatA, Ana; VeIGA, Maria do Rosário; Velosa, Ana Luísa; TAVARES, Martha Lins. Casos de estudo: metodologia de diagnóstico e soluções de reparação para revestimentos com problemas de umidade em edifícios antigos. In: Anais do IX SBTA - Seminário Brasileiro de Tecnologia de Argamassas. Belo Horizonte: Antac, 2011. 
JORNET, Albert; MOSCA, Cristina; CAVALLO, Giovanni; CORREDIG, Guido. Comparison between Traditional, Lime Based, and Industrial, Dry Mortars. In: Proceedings of the $2^{\text {nd }}$ Historis Mortars Conference and of the Final Workshop TC 203-RHM.Bagneux: RILEM Publications s.a.r.I, 2010.

KANAN, Maria Isabel. Manual de conservação e intervenção em argamassas e revestimentos à base de cal. Brasília, DF: Iphan / Programa Monumenta - Cadernos Técnicos - n. 8, 2008.

Experiences to conserve the lime fabric of our built heritage ilustrated by Santa Catarina's island, Brazil. In: $1^{\text {st }}$ Historical Mortars Conference. Characterization, Diagnosis, Conservation, Repair and Compatibilit. Final Workshop. Lisboa: LNEC, 2008. p. 565-572.

$\mathrm{KÜHL}$, Beatriz Mugayar. O tratamento das superfícies arquitetônicas como problema teórico da restauração. In: Anais do Museu Paulista - História e Cultura Material / Universidade de São Paulo, Museu Paulista, v.12 (jan/dez 2004). São Paulo: -, 2004. p. 309-330.

TAVARES, Martha. A conservação e o restauro de revestimentos exteriores em edifícios antigos: uma metodologia de estudo e reparação. Tese de Doutoramento, Universidade Técnica de Lisboa, Faculdade de Arquitetura, Laboratório Nacional de Engenharia Civil, Lisboa, 2009.

TAVARES, M. AGUIAR, J. VEIGA, R. Uma metodologia de estudo para conservação de rebocos antigos - o restauro através da técnica de consolidação. In: Anais do VI Simpósio Brasileiro de Tecnologia de Argamassas/ I International Symposium on Mortars Technology. Florianópolis: UFSC, 2005.

VEIGA, Maria do Rosário. Argamassas para revestimento de paredes de edifícios antigos. Características e campo de aplicação de algumas formulações correntes. In: Anais $3^{\circ}$ ENCORE Encontro sobre Conservação e Reabilitação de Edifícios. Lisboa: LNEC, 2003.

TEUTONICO, Jeanne Maria. A Laboratory Manual for Architectural Conservators. Roma: ICCROM, 1988. Disponível em:

http://www.iccrom.org/pdf/ICCROM_11_LabManual_en.pdf

\section{Agradecimentos}

Agradecemos à arquiteta doutora Maria Isabel Kanan, que prestou consultoria ao projeto de pesquisa, na formulação das argamassas-teste, por sua valiosa contribuição e por sua generosidade em compartilhar seu enorme conhecimento sobre o tema, e ao arquiteto MSc. Thiago Turino, por seu trabalho dedicado e competente no desenvolvimento da pesquisa, como bolsista do Programa de Incentivo à Produção do Conhecimento Técnico e Científico na Área da Cultura da FCRB.

\section{Claudia S. Rodrigues de Carvalho}

É arquiteta, formada pela Faculdade de Arquitetura e Urbanismo da UFRJ, mestre (1997) pelo PRO-ARQ-FAU/UFRJ, na área de concentração Conforto Ambiental, e doutora (2006) pelo Programa de Pós-graduação da Faculdade de Arquitetura e Urbanismo da Universidade de São Paulo. Realizou cursos de especialização em Preservação da Arquitetura Moderna no International Centre for Study of Preservation and Restoration of Cultural Property (1999) (ICCROM, Roma) e conservação preventiva no Center for Sustainable Heritage University College London (2003). É tecnologista sênior da Fundação Casa de Rui Barbosa e atualmente coordena as ações para preservação arquitetônica do Museu Casa de Rui Barbosa, no Centro de Memória e Informação.

claudiasrcarvalho@gmail.com 